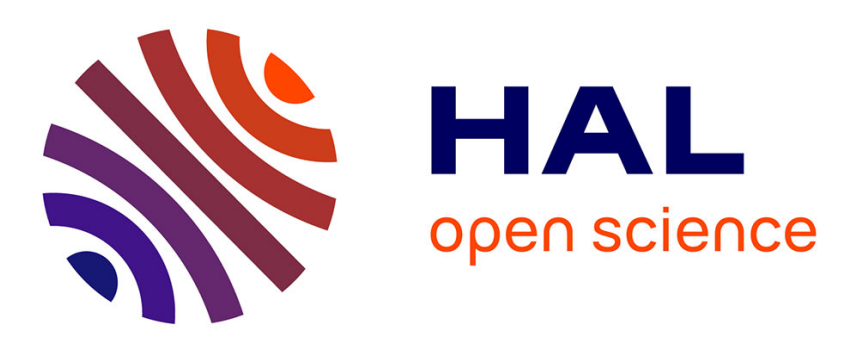

\title{
Behaviour modelling of aluminium alloy sheet for Single Point Incremental Forming
}

Nicolas Decultot, Vincent Velay, Laurent Robert, Gérard Bernhart, Elisabeth Massoni

\section{- To cite this version:}

Nicolas Decultot, Vincent Velay, Laurent Robert, Gérard Bernhart, Elisabeth Massoni. Behaviour modelling of aluminium alloy sheet for Single Point Incremental Forming. 11th ESAFORM Conference on Material Forming, Apr 2008, Lyon, France. pp.Pages 1151-1154, 10.1007/s12289-008-0184-z . hal00510321

\section{HAL Id: hal-00510321}

https://hal-mines-paristech.archives-ouvertes.fr/hal-00510321

Submitted on 18 Aug 2010

HAL is a multi-disciplinary open access archive for the deposit and dissemination of scientific research documents, whether they are published or not. The documents may come from teaching and research institutions in France or abroad, or from public or private research centers.
L'archive ouverte pluridisciplinaire HAL, est destinée au dépôt et à la diffusion de documents scientifiques de niveau recherche, publiés ou non, émanant des établissements d'enseignement et de recherche français ou étrangers, des laboratoires publics ou privés. 


\title{
Behaviour modelling of aluminium alloy sheet for Single Point Incremental Forming
}

\author{
N. Decultot ${ }^{1}$, V. Velay ${ }^{1}$, L. Robert ${ }^{1}$, G. Bernhart ${ }^{1}$, E. Massoni ${ }^{2}$, \\ ${ }^{1}$ Research Centre on Tools Materials and Processes (CROMeP) \\ Ecole Mines Albi - 81013 ALBI Cedex 9, France \\ URL:http://www.enstimac.fr/recherche/cromep \\ e-mail: \{nicolas.decultot, vincent.velay,laurent.robert,gerard.bernhart\}@enstimac.fr \\ ${ }^{2}$ Centre for Material Forming (CEMEF) \\ Ecole des Mines de Paris - BP 207 - 06904 Sophia-Antipolis, Cedex \\ URL: http://www-cemef.cma.fr/eng/welcome.html \\ e-mail: Elisabeth.massoni@ensmp.fr;
}

ABSTRACT: The aim of this work is to identify behaviour models of an aluminium alloy sheet formed by incremental stamping process by using both numerical simulations (FEM) and experimental procedures. The procedure developed will be used in Single Point Incremental Forming (SPIF) in using several original experimental tests allowing to reproduce loading paths close to those induced in the industrial operations and full-field measurements by 3D-Digital Image Correlation (DIC).

Key words: Incremental Forming, Numerical Simulations, 3D-Digital Image Correlation, Behaviour Models

\section{INTRODUCTION}

This paper refers to the new forming procedures used in sheet metal forming processes, commonly named Single Point Incremental Forming (SPIF) process. It is characterised by a high flexibility which allows an interesting technology improvement to manufacture sheet metal parts in controlling only a simple tool. Different steps of this process are shown in figure 1 [1]. Incremental displacements of the punch in various directions allow to form the sheet in order to provide the required shape.

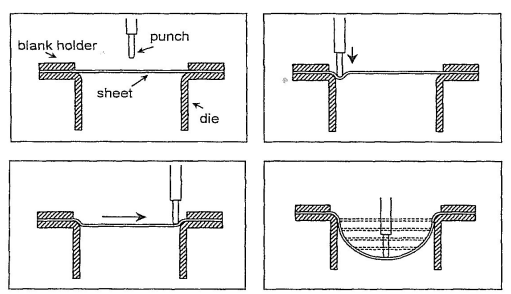

Fig. 1. Different steps of the Single Point Incremental Forming

Due to specific strain paths induced by the process and the fact that the plastic zone is strictly limited to the contact region between the tool and the workpiece, forming-limit curves and forming strategies are different from the classical deep drawing or stamping processes. Moreover this technology, in comparison with stamping process avoids using moulds and allows reducing costs when prototypes or batches have to be manufactured. However, Finite Element simulations are time-consuming because of the incremental characteristics of this process [2]. In this paper, we focus on the behaviour of an aluminium alloy 2024-T3 sheet that is forming with a incremental stamping test, process less complex than SPIF. Behaviour model parameters have been identified by tensile tests in 3 directions.

\section{EXPERIMENTAL TESTS}

\subsection{Tensile tests}

Simple tensile tests in 3 directions, $0^{\circ}$ (x axis), $45^{\circ}$ and $90^{\circ}$ have been performed and shown a weak anisotropy as shown in figure 2 .

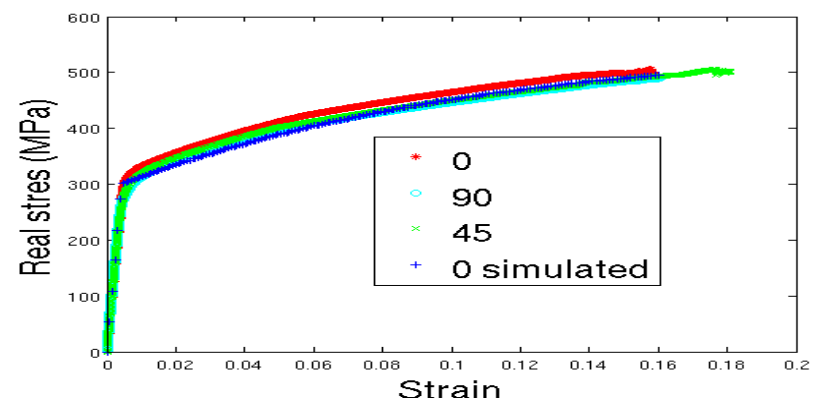

Fig. 2. Tensile tests in 3 directions and simulated tensile test identified by the $\mathrm{x}$-axis direction results (rational curve) 
The $\mathrm{x}$-axis simulated curve is used to identify the model behaviour parameters (see section 3.2)

\subsection{Incremental stamping test}

The incremental stamping test is carried out on a servo-electric tensile testing machine. The experimental set up is slightly modified in order to clamp the sheet and to consider the punch displacement to stamp it. The tool is $30 \mathrm{~mm}$ in diameter and presents a spherical active part like shown in figure 3. In this case, punch displacement and global force induced are measured.

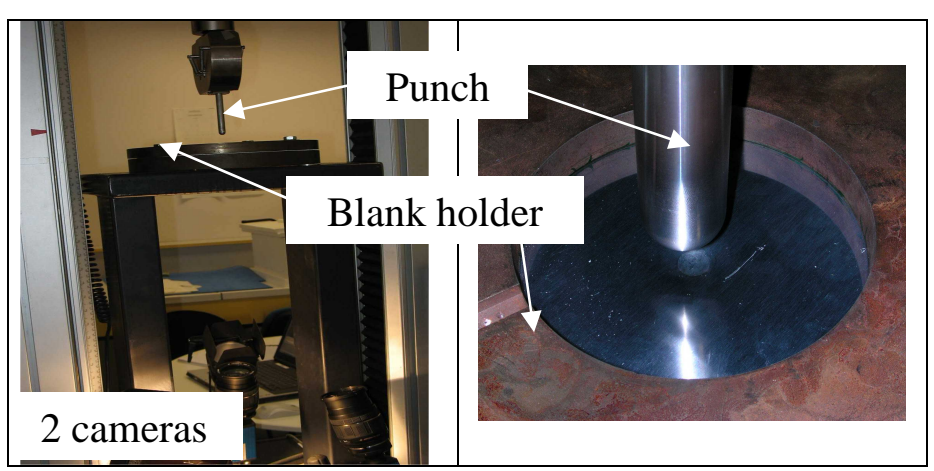

Fig. 3. Incremental stamping test

This device is also instrumented by a cameras stereo-rig in order to perform displacement/strain fields measurements by 3D-Digital Image Correlation (3D-DIC) [3] (Vic-3D ${ }^{\circledR}$ system).

\section{NUMERICAL SIMULATIONS}

\subsection{Meshing and boundary conditions}

Shell elements are used to model the sheet. Dimensions are $130 \mathrm{~mm}$ in diameter (internal diameter of the blank holder) and $1 \mathrm{~mm}$ in thickness. Finite Element (FE) calculation considers 9 integration points in the thickness and are performed with ABAQUS/explicit. The meshing is shown in figure 4 .

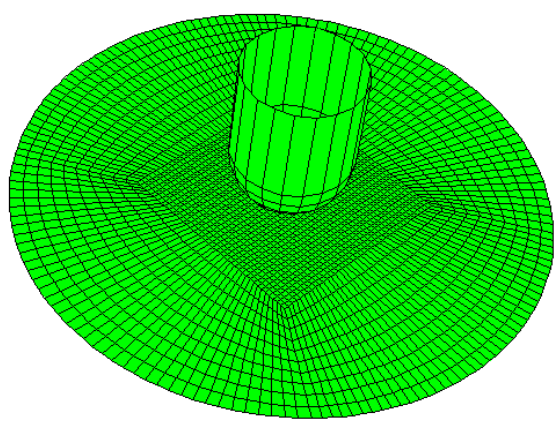

Fig. 4. ABAQUS meshing
The boundary conditions include a punch displacement, which are considered as a rigid body, and a clamping of all the external nodes. The value of the coefficient of friction is chosen equal to 0,2 according to stamping value found in the literature.

\subsection{Behaviour model}

In a first approach, elasto-plastic model is used. It includes a Von Mises yield criterion and an isotropic hardening law as presented in equations (1) and (2).

$$
\begin{aligned}
& f=\underline{\underline{\sigma}}_{e q}-R-R_{0} \\
& \mathrm{R}=\mathrm{Q}\left(1-\mathrm{e}^{\mathrm{-b} \lambda}\right)
\end{aligned}
$$

with:

$\mathrm{R}$ : Isotropic hardening law

$R_{0}$ : Yield strength

$\sigma_{e q}:$ Von Mises equivalent stress

$\mathrm{Q}$ et $\mathrm{b}:$ Materials parameters

The plastic multiplier, $\lambda$ is calculated from the consistency condition, $f=\dot{f}=0$. Thus, it is deduced from the relation $\frac{\partial f}{\partial \underline{\sigma}}: \underline{\underline{\sigma}}+\frac{\partial f}{\partial R} \dot{R}=0$.

$\dot{\lambda}=H(f) \frac{1}{h}\left\langle\frac{\partial f}{\partial \underline{\underline{\sigma}}}: \underline{\underline{\sigma}}\right\rangle$ where $\mathrm{h}=\mathrm{b}(\mathrm{Q}-\mathrm{R})$.

Parameters of the elasto-plastic model have been identified with $\mathrm{x}$-axis direction tensile test. The following values have been found:

$R_{0}=300 \mathrm{MPa} ; Q=250 \mathrm{MPa} ; b=10 ; E=70000 \mathrm{MPa}$ (Young Modulus).

\section{RESULTS}

First, some displacement/strain fields measurements obtained by 3D-DIC are shown in figure 5: (a) outof-plane displacement field, (b) longitudinal and (c) shear strain fields, for an imposed tool displacement of $4 \mathrm{~mm}$ corresponding to a $900 \mathrm{~N}$ force. The Area Of Interest (AOI) presented in figure 5 corresponds to almost the cameras field of view. On this area an experimental mesh (3D points cloud) is built. Results provided by 3D-DIC are the shape (3D points cloud) and the displacement vector at each point. 


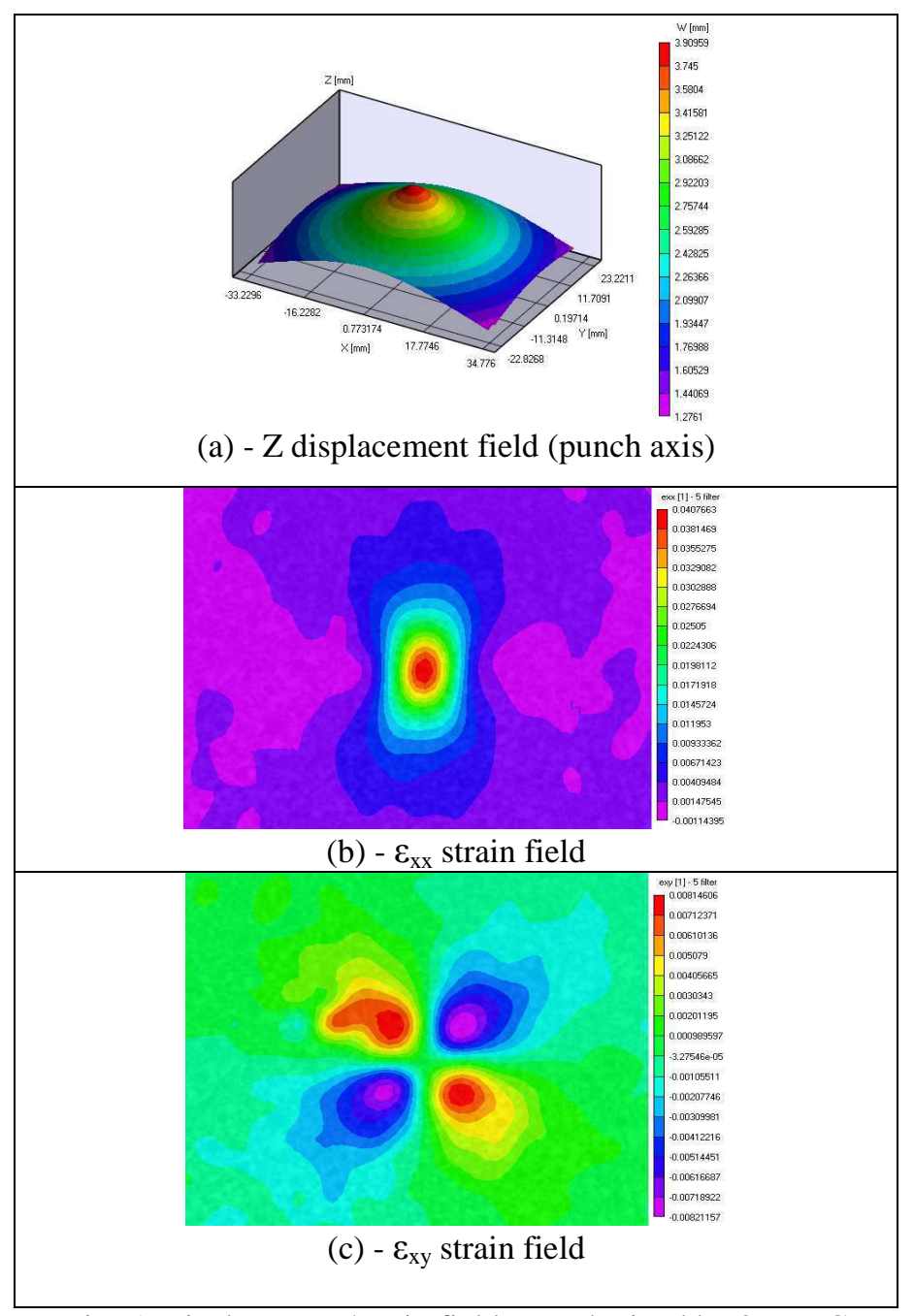

Fig. 5. Displacement/strain fields are obtained by 3D-DIC technique

Figure 6 presents the evolution of the global force versus punch displacement. FE response over assess the experimental curve for a punch displacement up to $4 \mathrm{~mm}$. Crack initiation of the sheet was observed for a punch displacement up to $15 \mathrm{~mm}$.

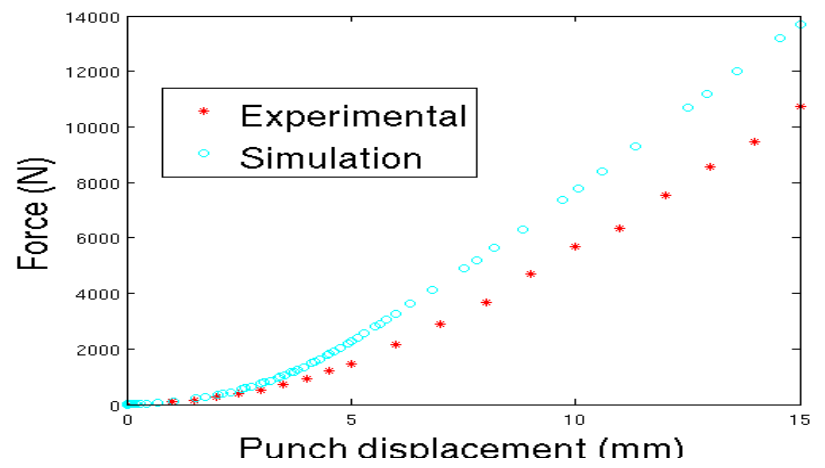

Fig. 6. Comparison between the experimental and simulated global force in function of the punch displacement

To explain these differences, several hypothesis are proposed. First of them concerns the study of clamping boundary condition influence.
In the model, the sheet dimensions was reduced to the dimensions of the AOI. The experimental mesh provided by the 3D-DIC computation was projected on the FE mesh as shown in figure 7. For each FE mesh node of the external AOI, the measured displacement vectors of the corresponding experimental node are extracted as shown in figure 8. Thus, the displacement vectors of the AOI external nodes are imposed boundary conditions and the sheet is not more clamped.

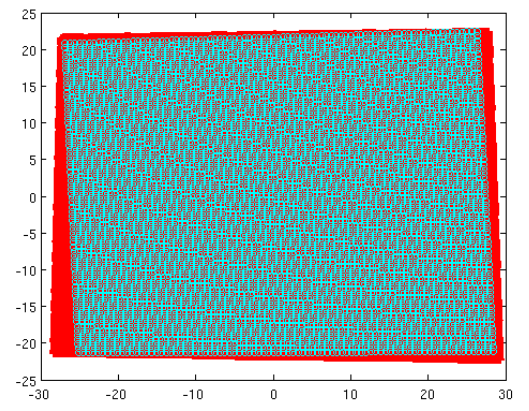

Fig. 7. FE mesh in blue circle and experimental mesh in red cross

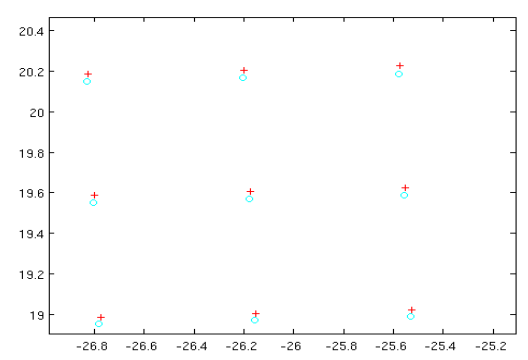

Fig. 8. Experimental nodes corresponding to FE mesh nodes

Figure 9 presents the evolution of the global force versus punch displacement for both the experimental measurement and this new simulation which takes care to the measured boundary conditions (simulation 2).

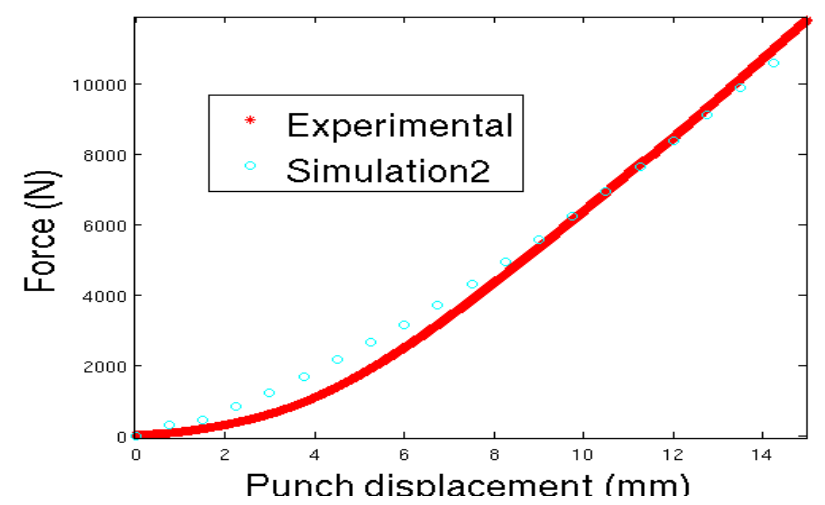

Fig. 9. Comparison between the experimental and the new simulated global force in function of the punch displacement

Taking into account true (measured) boundary conditions improves greatly the simulation results. 
However, the sheet tensioning in the incremental stamping test beginning can explain that FE response over assess the experimental curve for the lower punch displacement.

Figure 10 shows the 3D-DIC measured and the FE obtained sheet $\mathrm{z}$-displacement fields.

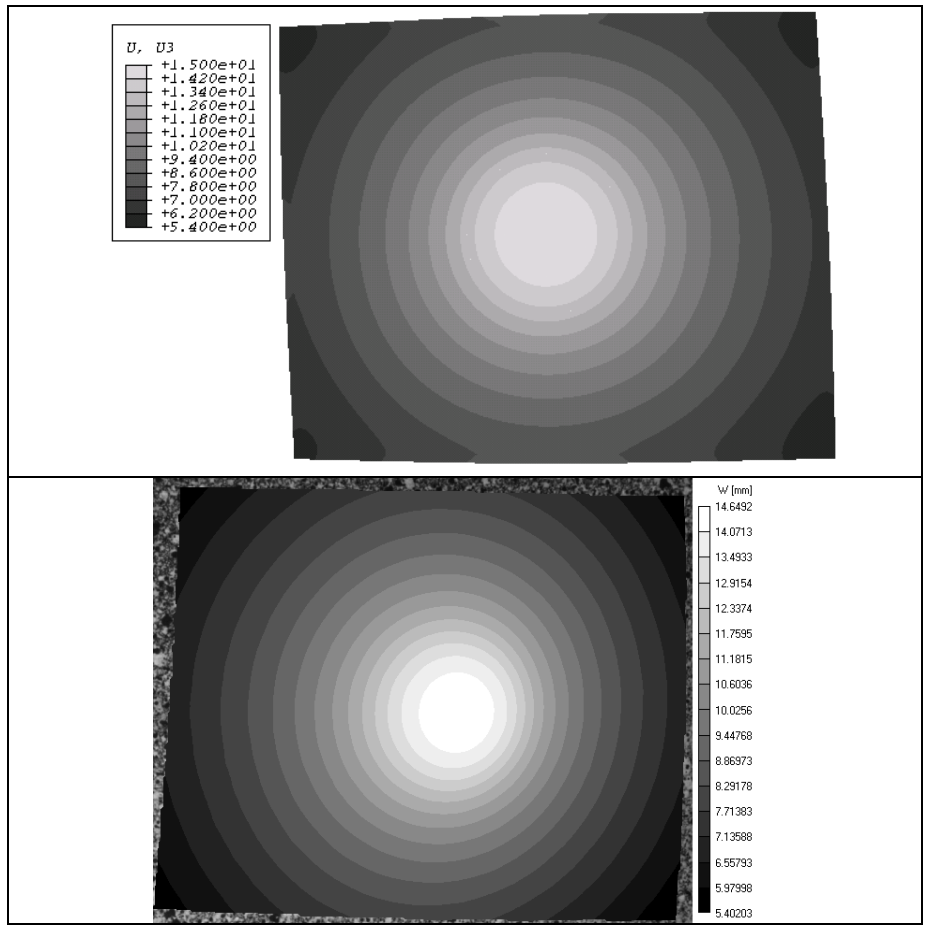

Fig. 10. 3D-DIC measured (bottom) and the FE results (top) sheet displacement fields for a $15 \mathrm{~mm}$ imposed punch displacement

For an imposed punch displacement of $15 \mathrm{~mm}$, the maximum sheet displacement measured by 3D-DIC is $14.65 \mathrm{~mm}$, about $2.33 \%$ error. The sheet thickness diminution ( $1 \mathrm{~mm}$ to $0,8 \mathrm{~mm}$ ), not considered by shell elements, can explain this difference.

\section{CONCLUSIONS AND DISCUSSIONS}

The comparison between experimental and FE displacements fields and evolution of the global force versus punch displacement give very similar results.

At this stage, strain fields values are quite different and work is going on about that point. Nevertheless, one can explain these differences:

- Vic-3D software and Abaqus do not use the same method to calculate strains.

- The boundary conditions in displacement for the external nodes add actually strains on the sheet border that are not observed in the experimental strain field.
- The behaviour model does not consider damage and sheet anisotropy.

Procedure used in incremental stamping (3D-DIC measures, imposed boundary conditions, model developed) will be used and improved for SPIF. In order to reproduce the strain paths observed in the industrial SPIF process, a SPIF test prototype is actually developed in the laboratory (see figure 11). This prototype is multi-instrumented (3D force sensor, 3D-DIC or multi-vision based DIC) and allows to generate complex shape pieces. The 3D force sensor of this prototype will allow to measure friction between punch and sheet.

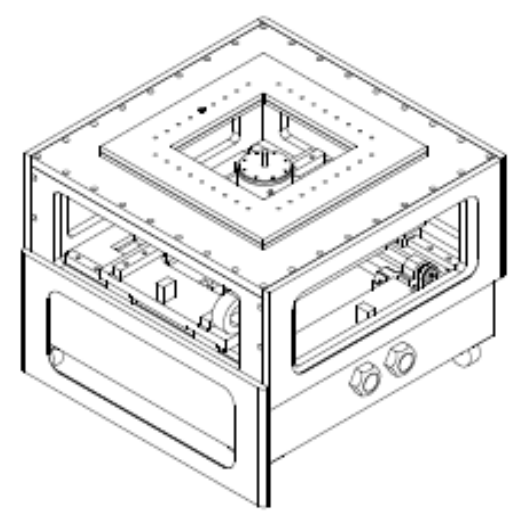

Fig. 11. SPIF test prototype

Tensile load-unload tests are carried out to quantify the sheet damage. Tensile tests using 3D-DIC are carrying out in order to identify more precisely anisotropic yield criterion. Finally, in the incremental forming process, the horizontal punch displacements on the sheet induce tensile and compressive stresses which will require an improvement of the behaviour model formulation

\section{REFERENCES}

1. T.J. Kim and D.Y. Yang, 'Improvement of formability for the incremental sheet metal forming process', International Journal of Mechanical Sciences, 42, (2000), pp. 1271-1286.

2. S. He, A. Van Bael, P. Van Houtte, Y. Tunckol, J. Duflou, C. Henrard, C. Bouffioux, A.M. Habraken, 'Effect of FEM choices in the modelling of incremental forming of aluminium sheets', Proc. $8^{\text {th }}$ ESAFORM conf., (2005), Cluj-Napoca, Romania

3. L. Robert, F. Nazaret, J-J. Orteu, T. Cutard, 'Use of 3-D Digital Image Correlation to characterize the mechanical behavior of a Fiber Reinforced Refractory Castable', Experimental Mechanics, 9(11) (2007), pp. 761-773. 